\title{
Effect of Humidity on Properties of Lithium-ion Batteries
}

Xiao Han, Saisai Xia, Jie Cao, Chris Wang, Ming-gong Chen*

School of Earth and Environment of Anhui University of Science and Technology, Anhui, China, 232001

*E-mail: zxky@aust.edu.cn

doi: $10.20964 / 2021.05 .54$

Received: 19 September 2020 / Accepted: 25 January 2021 / Published: 31 March 2021

\begin{abstract}
A study was performed to determine the cause of abnormal direct current resistance (DCR) during hightemperature storage of a commercialized lithium-ion battery $(1 \mathrm{C}=50 \mathrm{Ah})$ designed for an electrical vehicle. Scanning electron microscopy, energy-dispersive X-ray spectroscopy, inductively coupled plasma atomic emission spectroscopy, air permeability measurements and electrochemical impedance spectroscopy were used to analyze batteries with abnormal and normal DCRs. The results of these analyses show that imperfect solid electrolyte interface formation increases the direct current resistance. This imperfection results from the presence of excessive moisture during battery production.
\end{abstract}

Keywords: Excess moisture; Lithium-ion battery; Imperfect solid electrolyte interface; Direct current resistance

\section{$\underline{\text { FULL TEXT }}$}

(C) 2021 The Authors. Published by ESG (www.electrochemsci.org). This article is an open access article distributed under the terms and conditions of the Creative Commons Attribution license (http://creativecommons.org/licenses/by/4.0/). 